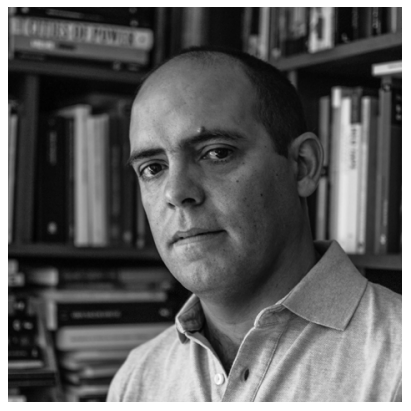

Ramiro Segura

Antropólogo. Doctor en Ciencias Sociales Laboratorio de Estudios en Cultura y Sociedad, Facultad de Trabajo Social (UNLP) Instituto de Altos Estudios Sociales (UNSAM) CONICET segura.ramiro@gmail.com

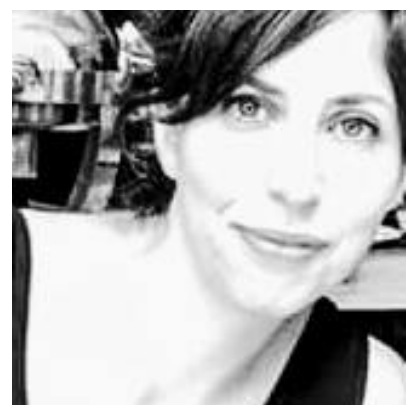

Natalia Cosacov

Socióloga. Doctora en Ciencias Sociales Instituto de Investigaciones Gino Germani, Facultad de Ciencias Sociales (UBA) y CONICET nataliacosacov@gmail.com

\title{
Políticas públicas de vivienda: impactos y limitaciones del Programa ProCreAr
}

Resumen: Se analizan los impactos y limitaciones del Programa de Crédito Argentino del Bicentenario para la Vivienda Única Familiar (ProCreAr), política pública contracíclica que buscó combinar la dinamización de la economía y la generación de empleo con el acceso a la vivienda por parte de los sectores medios. La ausencia de una política clara en la producción y la regulación del suelo urbano explica la existencia de desacoples entre las dimensiones macroeconómicas y territoriales del programa, que se expresan no sólo en el déficit de suelo urbano al momento de su implementación sino también en los efectos urbanos de la propia implementación. Se discuten además los desafíos y las potencialidades que el hábitat -como realidad multidimensional que incluye factores económicos, sociales y ambientales- tiene para el desarrollo social y productivo del país y el lugar que la ciencia y la tecnología podrían ocupar en esos procesos. Palabras clave: política pública, vivienda, suelo urbano, ProCreAr

\section{Public housing policies: impacts and limitations of ProCreAr Program}

Abstract: We analyze the impacts and limitations of the Argentine Bicentennial Credit Program for Single Family Housing (ProCreAr), a countercyclical public policy that sought to combine the revitalization of the economy and the generation of employment with access to housing by the middle sectors. The absence of a clear policy in the production and regulation of urban land explains the existence of decoupling between the macroeconomicand territorial dimensions of the program, whichareexpressed notonly in the deficitofurban land at the time of its implementation but also in the effects of the implementation itself. The challenges and potentialities that habitat - as a multidimensional reality -have for the social and productive development of the country are discussed. As well as the place that science and technology could take in those processes. Keywords: public policy, housing, urban land, ProCreAr 


\section{Políticas públicas de moradia: impactos e limitações do ProCreAr}

Resumo: Este artigo reflete sobre o impacto e as limitações do Programa Argentino de Crédito do Bicentenário para a Moradia Unifamiliar (ProCreAr), política pública anticíclica que procurou combinar o dinamismo da economia e geração de emprego com acesso à habitação por os setores médios. A ausência de uma política clara na produção e regulação do território urbano explica a existência da dissociação entre as dimensões macroeconômicas e territoriais do programa, que expressa-se não apenas no déficit do solo urbano, no momento da sua execução, mas também nos efeitos urbanos da implementação em si. Serão ainda discutidos os desafios e potencialidades que o habitat - como uma realidade multidimensional - têm para o desenvolvimento social e produtivo do país, bem como o lugar que a ciência e a tecnologia poderiam ocupar nesses processos.

Palavras-chave: política pública - habitação - terreno urbano - ProCreAr

\section{Introducción}

En junio de 2012, en un contexto de crisis económica internacional y estancamiento de la economía doméstica, el gobierno encabezado por Cristina Fernández de Kirchner lanzó el Programa de Crédito Argentino del Bicentenario para la Vivienda Única Familiar (en adelante, ProCreAr) por medio de la creación de un fondo fiduciario constituido con recursos del Estado nacional y con la participación del Banco Hipotecario, con los objetivos de facilitar el acceso a la vivienda propia y dinamizar el mercado de trabajo, previendo el otorgamiento de 400.000 créditos hipotecarios en los siguientes cuatro años.

El ProCreAr fue una política pública novedosa y de gran escala, orientada fundamentalmente a los sectores medios (Elimbaum y Barenboin, 2017) los cuales, pese a la sostenida mejora de los indicadores económicos y sociales desde 2003, no tenían acceso al mercado hipotecario y habían atravesado un proceso de inquilinización. Inicialmente los créditos se organizaron en dos grandes líneas: "líneas individuales" para propietarios de un terreno (créditos para la construcción, ampliación/terminación y/o refacción de la vivienda individual y/o familiar) y la línea de "desarrollos urbanísticos" (créditos para beneficiarios que no contaban con terreno, que suponían la construcción de viviendas multifamiliares por parte del programa). Entre las cualidades del crédito se destacaron las tasas beneficiosas, la extensión del plazo de pago a 30 años, la relación cuota-ingreso hasta el 40\%, la potencial inclusión de trabajadores que no se encontraran en relación de dependencia, entre otras. Por estos motivos -y tras largos años de poca oferta hipotecaria- el crédito fue percibido por la mayoría de los solicitantes y los beneficiarios como "una oportunidad única". Esta valoración ayuda a comprender el masivo interés en el crédito y los sucesivos récords de solicitantes.

Los datos en los que se basan estas reflexiones provienen de una investigación sobre los impactos económicos, sociales y territoriales del ProCreAr realizada en $2016^{1}$ desde el Instituto de Desarrollo

\footnotetext{
1 La investigación aborda la implementación del ProCreAr durante el gobierno de Cristina Fernández de Kirchner. En junio de 2016, con la Alianza Cambiemos en el gobierno, se relanzó el programa con el mismo nombre pero con modificaciones sustanciales en sus lógicas de financiamiento (los fondos no eran de la ANSES, pudiendo ofrecer créditos la banca privada) y en los criterios de otorgamiento (se abandonó el sorteo por un mecanismo de puntos). Este nuevo formato no será analizado en este artículo, aunque vale señalar que su relevancia en términos económicos y en la construcción efectiva de viviendas fue significativamente menor, hasta pasar prácticamente desapercibido poco tiempo después de su relanzamiento.
} 
Económico y Social (IDES) a solicitud del Banco Hipotecario. Para el trabajo de campo se seleccionaron distintas localidades del país aplicando los criterios de representatividad geográfica y variabilidad urbana, dentro de las localidades que al momento de la investigación contaban con viviendas finalizadas, no solo en las líneas de crédito individuales sino también en los desarrollos urbanísticos (que fue la línea que más demoró en implementarse): La Matanza (por el Conurbano Bonaerense), Tandil (por la provincia de Buenos Aires), Sierras Chicas, Córdoba (por el centro del país), Pocito, San Juan (por la región de Cuyo), Resistencia, Chaco (por el Noreste), Yerba Buena, Tucumán (por el Noroeste) y Comodoro Rivadavia y Puerto Madryn (por la Patagonia). Se conformaron seis equipos de tres investigadores/as. La dirección de la investigación estuvo a cargo de Ramiro Segura y la coordinación de los equipos locales estuvo a cargo de Natalia Cosacov. El proyecto contó, además, con el asesoramiento metodológico de Elizabeth Jelin.

La investigación constituyó, entonces, una experiencia productiva de diálogo y de trabajo compartido entre investigadores en ciencias sociales y ejecutores de una política pública, quienes estaban interesados en conocer -por medio de una investigación social- la eficacia del programa en distintas dimensiones de su implementación así como también identificar sus limitaciones. Habiendo analizado en otro lugar (Cosacov y Segura, 2017) la experiencia de los beneficiarios acerca de distintas dimensiones del crédito -dinámica de otorgamiento, gestión el crédito, valoraciones del acceso a la vivienda y transformaciones en el habitar cotidiano, entre otras- aquí nos detendremos en una reflexión sobre los impactos y las limitaciones de esta política pública en términos económicos y urbano-territoriales.

\section{El acceso al suelo urbano como factor limitante del programa}

El ProCreAr formó parte de un conjunto de políticas habitacionales nacionales poscrisis. En efecto, desde la crisis política, económica y social de 2001/2002 la política pública de vivienda no respondió exclusivamente al déficit habitacional persistente en el país, sino que también fue pensada como un motor para el desarrollo de estrategias de intervención económica y social más amplia (Di Virgilio y Rodríguez, 2018). Así, los planes federales de vivienda destinados a sectores populares primero (2003-2013) y, posteriormente, el crédito ProCreAr (2012-2015) destinado a sectores medios tuvieron, más allá de sus diferencias, objetivos convergentes que excedían la disminución del déficit habitacional: fueron pensados también con la finalidad de impulsar la reactivación económica y la generación de empleo.

A nivel nacional el impacto económico del ProCreAr se pudo percibir en la dinamización de la construcción y, consecuentemente, en el aumento de la demanda de empleo en el sector (tanto de profesionales como de trabajo manual), así como en la demanda de materiales. Las cifras al respecto son sorprendentes. En un informe elaborado por la Bolsa de Comercio para el año 2015 se destaca "el desempeño positivo" del sector de la construcción como consecuencia del "significativo impacto del ProCreAr" (AAVV, 2015: 72). La elevación de un 8,4 \% en la tasa de construcción se debió en gran medida al crecimiento en la construcción de viviendas, que representó el 53,36\% del total de las obras nacionales. Esta expansión de la construcción significó un incremento interanual en la demanda de pintura (11,4\%), ladrillos (10,1\%) y pisos y revestimientos (8,6\%). Si a estos datos le sumamos, además, los sucesivos records históricos en 
el consumo de cemento portland durante los años 2012, 2013, 2014 y 2015, llegando en este último año al máximo histórico desde 1977 de 12.125.014 toneladas, se tiene una imagen poderosa del rol del programa en la dinamización del sector. Del mismo modo, esta expansión del sector de la construcción se tradujo en la expansión de la demanda de mano de obra, que creció en 2015 un 7,1\% en empleados registrados, alcanzando los 416.325 trabajadores (sin contar los trabajadores no registrados).

En ciudades como Tandil, beneficiarios del programa y otros informantes relataron lo difícil que resultaba "conseguir un albañil" en los momentos de auge del crédito. Un maestro mayor de obra entrevistado sostuvo que en el rubro de la construcción hubo pleno empleo durante el "periodo del ProCreAr", afirmando que en sus 30 años de actividad, los últimos 4 años habían sido los que más trabajó. Y un arquitecto de esa localidad señaló: "hubo un momento en que era muy difícil encontrar un albañil porque todos tenían trabajo, los corralones explotaban de ventas. (...) incluso segundas líneas [albañil con poca experiencia] ya tenían su cuadrilla". Por su parte, en la provincia de Córdoba durante 2015 el promedio mensual de trabajadores en la construcción fue de 27.141 trabajadores, lo que significó un crecimiento del 7,9\% respecto del año anterior, solo contando los trabajadores registrados. Asimismo, vale señalar que en términos generales, en las localidades estudiadas, se destacó que el impacto del ProCreAr fue mayor en empresas pequeñas, inmobiliarias chicas y en jóvenes arquitectos, que en las grandes empresas constructoras, las inmobiliarias más importantes y los estudios de arquitectos consolidados.

De manera concomitante, esta dinamización del sector también impactó en el incremento de los precios del suelo y de los materiales, que se transformaron en un obstáculo o un límite para la expansión del programa. Aquí también las cifras son sorprendentes. Según el entonces titular de la ANSES, Diego Bossio, un relevamiento realizado por el organismo arrojó que los precios de los terrenos se incrementaron entre el 80 y el $110 \%$ en todas las provincias del país durante el primer año de implementación del programa (citado por Del Río, 2017: 278/279). En efecto, un significativo vacío en el diseño original del programa se relaciona con la ausencia de mecanismos de producción de suelo urbano y/o de regulación de los precios del suelo urbano disponible. Ante este escenario, la existencia de una gran cantidad de beneficiarios del programa en busca de un terreno para construir desató un fuerte proceso especulativo por parte de los propietarios en un contexto de escasez relativa de tierras. De esta manera, la principal debilidad del programa -que ayuda a explicar sus sucesivas transformaciones, como la posterior inclusión de nuevas líneas de crédito como compra de terreno, compra de vivienda a estrenar y producción de lotes con servicios- se relacionó con las crecientes dificultades para acceder a suelo urbano, tanto por su escasez relativa como por el exponencial proceso de especulación inmobiliaria que se registró en todo el país, acompañado por un correlativo incremento en la demanda y los precios de los materiales de construcción.

En este sentido, durante el período de implementación del programa se observa un desplazamiento en la opinión pública, agentes municipales e interesados en el crédito que va desde una gran expectativa inicial hacia el registro de problemas, conflictos y limitaciones producto de su funcionamiento. Así, por ejemplo, sobre 1004 beneficiarios encuestados por el Banco Hipotecario a mediados de 2015 que aún no habían iniciado los trámites para efectivizar el crédito, el 33\% tenía problemas con el acceso al terreno en el que construir. De estos, el $87,7 \%$ refirió problemas con los precios de los terrenos y el $12,3 \%$ restante con la escrituración. Estos problemas parecen haberse agudizado con el correr de los años, donde a la propia 
| Ciencia, Tecnología y Política | Año 2 | N² | Enero-Junio 2019 | ISSN 2618-3188 | www.revistas.unlp.edu.ar/CTyP |

especulación producto del impacto del programa, se le sumó un creciente contexto inflacionario. En este sentido, en 2016 el Defensor del Pueblo de la Provincia de Córdoba y el Instituto de Estadísticas (INEDEP) presentaron un informe sobre las problemáticas que enfrentaron los beneficiarios del ProCreAr en esa provincia. Basado en una encuesta a 376 beneficiarios, del estudio se desprende una creciente dificultad para culminar la vivienda dependiendo del momento de otorgamiento del crédito: mientras entre quienes obtuvieron el crédito en 2012 y 2013 sólo el 19,16\% tuvo algún problema en relación a la finalización de sus casas, el 76,4\% de quienes ingresaron al sistema del crédito entre 2014 y 2015 admitieron haber tenido problemas en torno al crédito y la finalización de las viviendas.

Vale señalar, sin embargo, que hay significativas diferencias locales en torno a estas cuestiones, vinculadas a las características de cada una de las localidades estudiadas, la escala urbana y la disponibilidad de tierras, que se traducen en un impacto diferencial del ProCreAr en lo relativo a la cantidad de créditos otorgados y su peso en relación a la población total de cada localidad. Asimismo, se verifica la relevancia de las articulaciones entre el programa y las instancias políticas provinciales y locales para superar o morigerar algunos de los factores limitantes que se encontraron en su implementación. Por último, estas diversas dimensiones ayudan a comprender el impacto urbano-territorial variable del programa en cada una de las localidades analizadas. Serán estas cuestiones las que abordaremos en lo que queda de este artículo.

\section{Relaciones entre créditos otorgados, población y características de las localidades}

Los impactos urbano-territoriales del programa fueron geográficamente diferenciales y distintas dimensiones urbanas (escala, forma y dinámica) ayudan a comprender esas diferencias. En la Tabla $N^{0} 1$ se muestra el número de créditos de las líneas individuales otorgados en las localidades estudiadas en relación a la población de cada una de ellas. De esta tabla se desprende el impacto diferencial de los créditos ProCreAr en relación al total de la población de cada una de las localidades bajo análisis. Nótese, por ejemplo, que el municipio más pequeño de la muestra (Yerba Buena) tiene en términos absolutos

\begin{tabular}{|c|c|c|c|}
\hline Locación & Población $^{2}$ & Beneficiarios & Porcentaje \\
\hline La Matanza & 1.772 .130 & 1080 & 0,06 \\
\hline Tandil & 132.199 & 2067 & 1,56 \\
\hline $\begin{array}{c}\text { Colón } \\
\text { (Sierras Chicas) }\end{array}$ & 225.151 & 3651 & 1,62 \\
\hline $\begin{array}{c}\text { Escalante } \\
\text { (Comodoro Rivadavia) }\end{array}$ & 186.583 & 327 & 0,18 \\
\hline $\begin{array}{c}\text { Biedma } \\
\text { (Puerto Madryn) }\end{array}$ & 82.883 & 620 & 0,75 \\
\hline Yerba Buena & 75.076 & 1375 & 1,83 \\
\hline Resistencia & 290.723 & 1587 & 0,55 \\
\hline
\end{tabular}

Tabla $N^{\circ}$ 1. Relación entre créditos (línea individual) y población Fuente: Elaboración propia a partir de datos del INDEC y Banco Hipotecario. ${ }^{2}$ Censo Nacional 2010 realizado por el INDEC. Los datos fueron brindados por el Banco Hipotecario y están actualizados al 19/08/2016.

\begin{tabular}{|c|c|c|c|}
\hline Locaciones & Solicitudes & Beneficiarios & $\begin{array}{c}\text { Porcentaje } \\
\text { de Obras } \\
\text { Finalizadas }\end{array}$ \\
\hline La Matanza & 9038 & $1080(12 \%)$ & $87 \%$ \\
\hline Tandil & 5423 & $2067(38 \%)$ & $86 \%$ \\
\hline $\begin{array}{c}\text { Colón (Sierras } \\
\text { Chicas) }\end{array}$ & 6825 & $3651(51 \%)$ & $91 \%$ \\
\hline $\begin{array}{c}\text { Escalante } \\
\text { (Comodoro } \\
\text { Rivadavia) }\end{array}$ & 1676 & $327(20 \%)$ & $88 \%$ \\
\hline $\begin{array}{c}\text { Biedma (Puerto } \\
\text { Madryn) }\end{array}$ & 1993 & $620(31 \%)$ & $87 \%$ \\
\hline Yerba Buena & 3469 & $1375(40 \%)$ & $89 \%$ \\
\hline
\end{tabular}

Tabla $N^{\circ}$ 2. Relación entre solicitudes, beneficiarios y avance de obra en líneas individuales.

Fuente: Elaboración propia a partir de datos del Banco Hipotecario 
más créditos otorgados que ciudades medias (como Puerto Madryn y Comodoro Rivadavia) y grandes (como La Matanza) y, por lo tanto, el impacto de los créditos en relación al total de la población es mucho mayor (de 1,83\% en Yerba Buena a 0,06\% en La Matanza).

La escala urbana, entonces, puede ayudar a comprender este impacto diferencial del programa en la cantidad de créditos otorgados y viviendas construidas en relación a la población de cada una de las localidades. Si tenemos en cuenta, además, que el promedio nacional de otorgamiento de créditos de la línea individuos era a mediados de 2016 del 33\% (relación entre créditos solicitados y créditos otorgados a nivel general), de la tabla $N^{\circ} 2$ se desprende que locaciones pequeñas y medianas como Colón (51\%), Yerba Buena (40\%) y Tandil (38\%) se encuentran claramente por encima de la media, mientras que ciudades medias y grandes como La Matanza (12\%), Comodoro Rivadavia (20\%) y Resistencia (23\%) se encuentran sensiblemente por debajo.

Sin embargo, la escala no es la dimensión fundamental para la explicación de la variabilidad, ya que municipios similares en términos de población como Tandil y Escalante (ambos alrededor de 150.000 habitantes) o como Yerba Buena y Biedma (ambos rondando los 75.000 habitantes) han mostrado comportamientos marcadamente diferenciales en los alcances del crédito. En este sentido, de los resultados de la investigación se desprenden otras dimensiones relevantes como la estructura y dinámica urbana, la disponibilidad y precios de suelo urbano, los perfiles socio-económicos de los solicitantes y la capacidad de articulación política entre distintos niveles de gobierno (nacional, provincial y/o municipal) para viabilizar el crédito. Así, localidades con disponibilidad de terrenos próximos a centros urbanos mayores (como Yerba Buena con Tucumán y las Sierras Chicas con Córdoba, capitales provinciales que en el mencionado informe de la ANSES se encontraban entre los 25 distritos donde el problema del acceso al suelo urbano era crítico) fueron lugares en los que predominantemente sectores de clases medias solicitaron, recibieron y efectivizaron gran cantidad de créditos en las líneas individuales, mientras que esto no ocurrió en la misma medida en ciudades patagónicas de escalas urbanas similares.

Como decíamos, las Sierras Chicas en Córdoba (particularmente el departamento de Colón) y Yerba Buena en Tucumán tienen una situación urbana análoga: disponibilidad de terrenos a precios más accesibles que las respectivas ciudades cabecera, de las cuales a su vez se encuentran próximas en términos de distancia. Esta ecuación de disponibilidad (de suelos), relativa accesibilidad (de precios) y proximidad (a la ciudad capital) permite comprender que incluso con anterioridad al lanzamiento del ProCreAr estas localidades asistieran a un proceso de crecimiento poblacional, expansión urbana y progresiva conurbación con las respectivas ciudades cabecera. En efecto, la población del departamento de Colón creció un 31,62\% entre 2001 y 2010, representando el mayor crecimiento poblacional de toda la provincia, y Yerba Buena concentraba ya en 2007 la mayor cantidad de urbanizaciones cerradas del aglomerado urbano (49), convirtiéndose en uno de los municipios con mayor crecimiento demográfico de la provincia (Malizia y Paolasso, 2009). En localidades como estas, el ProCreAr reforzó tendencias urbanas preexistentes, siendo Colón el departamento con mayores créditos otorgados dentro de la provincia de Córdoba y Yerba Buena el segundo municipio de la provincia detrás de la capital.

El impacto del ProCreAr en las localidades patagónicas analizadas, en cambio, fue mucho menor. La causa principal de esta situación radica en la poca disponibilidad de suelo urbano y/o los elevados pre- 
cios del mismo. En el caso específico de Comodoro Rivadavia los altos precios del suelo debido tanto a limitantes naturales (topografía de la ciudad) como económicos (explotación de hidrocarburos) han sido una constante, generando un déficit sistemático de viviendas que se intensifica con el crecimiento de la población en contextos de boom petrolero como el de la primera década y media del siglo XXI (Bachiller, 2015). Además de los altos precios (que muchos informantes entrevistados no vinculan de manera directa al ProCreAr), se debe tener en cuenta que se calcula que al menos un 30\% de la población vive en terrenos que no cuentan con titularidad, lo que obtura la gestión de créditos hipotecarios.

\section{La articulación política}

Además de la disponibilidad de terrenos, la accesibilidad económica de sus precios y su cercanía a áreas centrales, una dimensión que hizo la diferencia para dar respuesta a los problemas de implementación fueron las capacidades político-institucionales locales en el marco del cual se desplegó el ProCreAr. En efecto, la investigación realizada evidencia que las capacidades político-institucionales locales fueron un factor clave (aunque no determinante) en el proceso de implementación. En particular, la capacidad para generar innovaciones o reingenierías normativas e institucionales que se dieron en algunas localidades, parece ser un factor diferencial a la hora de comprender los impactos disímiles en cada localidad.

Podríamos construir idealmente una línea que va desde casos como Comodoro Rivadavia (con severos problemas de tierras y nula articulación política), pasa por casos como La Matanza, Tucumán y Chaco (donde desde el Estado provincial y/o municipal se buscaron alternativas, que resultaron una resolución parcial a las problemáticas), hasta experiencias como la de Tandil (con fuertes y eficaces articulaciones políticas). Por motivos ciertamente excepcionales, este último caso suma un rasgo innovador: mostró una coalición por objetivos locales, al trabajar conjuntamente niveles de gobierno de distinto signo político. El Director Ejecutivo de la ANSES durante el período 2009- 2015, Diego Bossio, además de haber nacido en Tandil, continuó teniendo una estrecha relación con la política local, punto que se reflejó en la implementación del ProCreAr en la ciudad. Por un lado su hermano, Pablo Bossio, fue durante ese periodo concejal municipal y varios de los actores entrevistados mencionaron en distintos pasajes reuniones y encuentros con él sobre temas relativos al programa. Por otro lado, el Director de la ANSES manifestaba públicamente su intención de que "Tandil se convierta en un modelo de gestión del Programa en la provincia de Buenos Aires", dato que confirmó un alto funcionario entrevistado al afirmar: "Lo que pasa es que Tandil es el hijo pródigo del ProCreAr. Contábamos con que Diego es de Tandil y era director de la ANSES y yo tenía toda la presión de Diego que me decía: Che, sácame bien esto". Además, a pesar de que el gobierno local (UCR) era de signo opositor al entonces gobierno nacional (FPV), se mantuvo durante el periodo una actitud "colaborativa" en la implementación del Programa, lo cual derivó en una relación fluida entre los tres niveles de gobierno, el Banco Hipotecario y la ANSES. Esta articulación entre instancias se evidencia en la intensa actividad legislativa relativa al ProCreAr en el caso de Tandil, que contrasta con otras locaciones analizadas. Durante 2012-2015 se identificaron en la localidad 37 ordenanzas en relación al programa, algunas de las cuales regulan situaciones específicas de ciudadanos, mientras que otras manifiestan el apoyo municipal al éxito del programa: la declaración del ProCreAr de interés municipal, la firma de un Convenio de Colaboración, el cambio de normativas urbanísticas, la 
afectación y cesión de terrenos fiscales y la caratulación de los expedientes vinculados al programa como "Trámite Preferencial Urgente", entre otras. La gran cantidad de créditos concretados en la ciudad, la producción de lotes con servicio y la concreción de un desarrollo urbanístico en tierras que con anterioridad eran propiedad del ejército se explican -al menos en parte- por esta articulación.

Por supuesto, como venimos diciendo, este no es el único factor. En La Matanza, por ejemplo, existió una poderosa articulación entre distintos actores centrales en la implementación del programa: la sede local del Banco Hipotecario, la sede local de la Unidad de Atención Integral de la ANSES, el Presidente del Consejo Deliberante, la Secretaría de Hacienda y de Planeamiento Urbano del Municipio actuaron en conjunto "para buscarle la vuelta" a la gestión local del ProCreAr. De hecho, la promoción del programa en La Matanza adquirió las características de una verdadera "actividad militante" por parte de diversos agentes, que implicó recorrer barrios, plazas y lugares de trabajo difundiendo el programa y generando solicitudes. La Matanza representa, sin embargo, un caso límite al respecto: el voluntarismo desplegado a partir de la asociación entre una multiplicidad de agencias no fue suficiente para sobreponerse a un conjunto de factores limitantes: escala de la localidad, escasa disponibilidad y altos precios del suelo, dolarización del mercado inmobiliario, perfil socio-económico de solicitantes, entre otras.

En síntesis, para cada localidad analizada es posible pensar la implementación y ejecución del Programa en una interacción entre factores limitantes -que en cada territorio asumen intensidades diferentes- y un conjunto de atributos o capacidades político-institucionales que permitieron mediante la adecuación y desarrollo de estructuras de intervención, una mayor capacidad estratégica y de gestión del programa. Podríamos pensar, entonces, que las cambiantes ecuaciones entre la estructura urbana de cada ciudad, los factores limitantes y las capacidades político-institucionales -a lo que habría que incluir, además, las demandas y formas de organización novedosas de los beneficiarios²- se expresaron en "arreglos urbanísticos particulares", como los denominó Del Río (2017) a partir de su estudio de caso sobre La Plata, en cada localidad.

\section{Impactos urbano-territoriales del programa}

Como se desprende de lo que venimos diciendo, el suelo urbano como factor limitante para la implementación del programa constituye solo una de las facetas del problema. La otra cara remite directamente a los impactos territoriales de los distintos "arreglos urbanísticos particulares" que adquirió en cada localidad la implementación del programa. Ante la ausencia de herramientas eficaces para intervenir en la disponibilidad y la provisión de suelo así como de capacidades para regular los precios del suelo urbano, la implementación del programa en cada localidad estuvo en gran medida mediada y orientada por el mercado inmobiliario.

Si bien merece señalarse que la producción de lotes con servicios y los desarrollos urbanísticos (los pocos finalizados para 2016, los iniciados y también los frustrados³) buscaron desplegar otras lógicas,

\footnotetext{
${ }^{2}$ Si bien no lo podemos abordar aquí, uno de los fenómenos más interesantes de un crédito dirigido a individuos y familias fue el proceso de "colectivización" que desató desde sus inicios y que acompañó las distintas etapas del crédito en formas de colaboración que fueron desde la socialización de la información hasta la creación de "barrios ProCreAr".
} 
produciendo suelo urbano, densificando la trama e, incluso, interviniendo y buscando modificar las dinámicas y jerarquías urbanas preexistentes, la tendencia dominante en la implementación del programa fueron las líneas de crédito individual que, como se desprende de la tabla $\mathrm{N}^{0} 3$, constituyen la inmensa mayoría de los créditos otorgados y efectivizados (84,8\%).

\begin{tabular}{|l|l|l|l|l|}
\hline Créditos & $\begin{array}{l}\text { Líneas } \\
\text { individuales (LI) }\end{array}$ & $\begin{array}{l}\text { Desarrollos } \\
\text { Urbanísticos (DU) }\end{array}$ & $\begin{array}{l}\text { Lotes con } \\
\text { servicios }\end{array}$ & Totales \\
\hline Cantidad & 189014 & $\begin{array}{l}70 \mathrm{DU}=23629 \\
\text { viviendas }\end{array}$ & 10404 & 223.047 \\
\hline Porcentaje & $84,8 \%$ & $10,5 \%$ & $4,7 \%$ & $100 \%$ \\
\hline
\end{tabular}

Tabla N³. Distribución de los créditos a mediados de 2016 Fuente: Elaboración propia a partir de datos del Banco Hipotecario (2016).

En este sentido, en términos generales se puede afirmar que, en tanto el acceso al suelo estuvo mayoritariamente mediado por el mercado inmobiliario, el ProCreAr-carente de capacidades y herramientas para eludir o matizar sus condicionamientos- acompañó, reforzó y/o profundizó tendencias urbanas preexistentes, que en cada localidad asumen rasgos particulares:

- La migración hacia Sierras Chicas de sectores medios residentes en la ciudad de Córdoba.

- El crecimiento hacia el Norte de la expansión urbana de la ciudad de Tandil.

- La expansión de barrios cerrados en Yerba Buena, Tucumán.

- La progresiva urbanización de la zona sur (incluyendo la localidad vecina de Rada Tilly) y zona sudoeste en Comodoro Rivadavia, así como el sur y el oeste de Puerto Madryn.

- La progresiva urbanización de la zona sur del Partido de La Matanza, en particular Virrey del Pino y, al mismo tiempo, el desarrollo de zonas ya consolidadas (como San Justo).

De esta manera, ante la ausencia de definiciones claras en materia de producción, acceso y precios del suelo urbano, las dinámicas del mercado continuaron definiendo el acceso a la vivienda, profundizando las tendencias hacia una expansión urbana más extensa y difusa, con los consabidos costos ambientales, sociales y económicos a mediano y largo plazo.

\section{Comentarios y conclusiones}

Tres breves notas, a modo de recapitulación, sobre el ProCreAr y una reflexión sobre las relaciones entre ciencia, tecnología y desarrollo para finalizar.

La primera nota consiste en destacar el valor de una política pública con un horizonte inclusivo, que simultáneamente buscó reactivar la economía, generar empleo y garantizar el acceso a la vivienda en un

\footnotetext{
${ }^{3}$ Además de ser menos, los desarrollos urbanísticos avanzaron más lentamente que los créditos individuales (para 2016 había muy pocos finalizados) y en la implementación se desplegaron temporalidades antagónicas: "el vértigo" de las líneas individuales y "la espera" de los desarrollos urbanísticos (Cosacov y Segura, 2017). Una investigación aparte mecerían todos los proyectos de Desarrollos Urbanísticos del programa que fueron resistidos en distintas ciudades del país. Para el caso de Mar del Plata, ver Canestraro (2016)
} 
contexto macroeconómico complejo: crisis internacional, estancamiento económico, dolarización del mercado inmobiliario e inflación. A partir de los resultados obtenidos sostenemos, sin embargo, que durante la implementación del programa existió un "desacople" (Segura, 2017) entre las dimensiones económicas y territoriales del programa, observándose desajustes entre la política macroeconómica contracíclica y las políticas urbanas a nivel local (Del Río, 2017).

Asimismo, si queremos comprender estos desacoples entre los distintos objetivos del programa y las dificultades surgidas en su implementación, la segunda nota consiste en volver a colocar en el centro no solo la generación de las condiciones para el acceso al crédito, sino también la necesidad imperiosa de instrumentar nuevos mecanismos y capacidades en el sector público para intervenir en la producción de suelo urbano y en la regulación de su precio, orientados por los principios de la ciudad como bien común y buscando garantizar no solo el acceso a la vivienda sino también el derecho a la ciudad. Al respecto, resulta relevante (aunque insuficiente en términos efectivos) los aprendizajes sobre la marcha que el propio programa fue dando, al crear nuevas líneas de crédito que contemplaban esta dimensión clave de la política urbana.

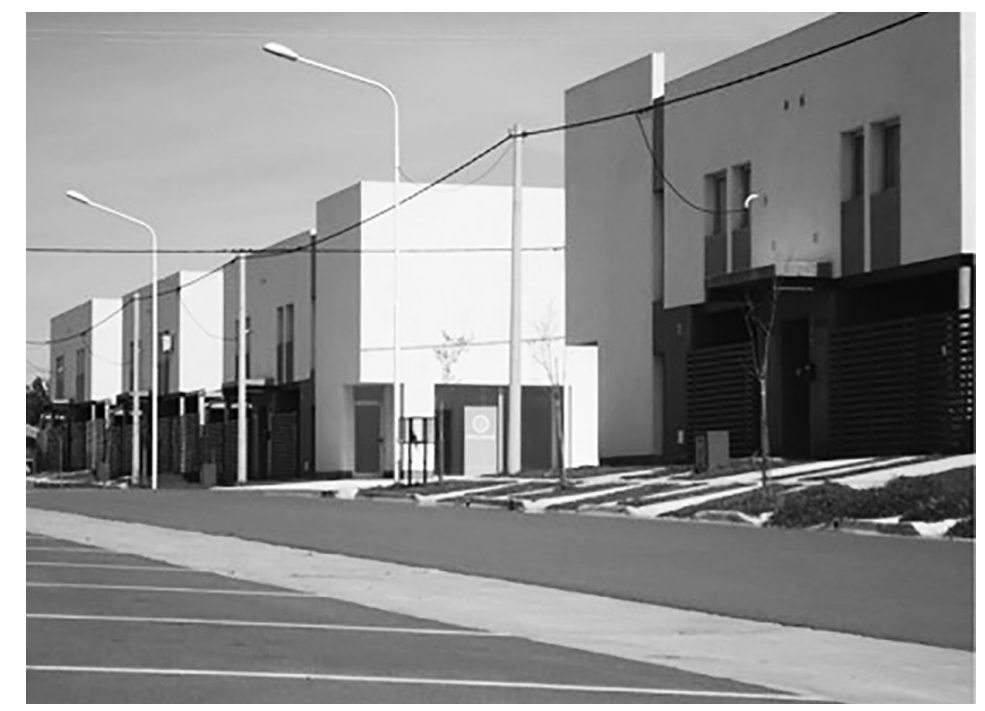

Desarrollo urbanístico implementado con el programa procrear, Tandil, Buenos Aires

Por último, la tercera nota remite al necesario reconocimiento de que la cuestión del suelo urbano tiene, en un programa como el ProCreAr, una doble faceta: por un lado, fue el principal factor limitante a la hora de la implementación del programa, generando especulación, conflictos e incluso que algunos beneficiarios perdieran su crédito; por el otro, sin una regulación clara y en gran medida comandado por el mercado inmobiliario, el ProCreAr reforzó y/o profundizó ciertas tendencias en la producción del espacio urbano que suponen altos costos (sociales, económicos y ambientales) en el mediano y largo plazo, cuando el desafío a futuro consiste en pensar cómo y por qué medios un programa de este tipo podría llegar a revertirlos.

En pos de este objetivo, las ciencias sociales tienen indudablemente aportes que realizar a la política 
pública. No solo en el sentido de evaluar o auditar sus resultados, como el caso de nuestra investigación. Pensamos, en cambio, que el saber acumulado a partir del análisis de diversas experiencias concretas que permitió identificar potencialidades, limitaciones y omisiones en las políticas de vivienda, debería retroalimentar la formulación, el diseño y la implementación de futuras políticas públicas del sector, articulando de manera virtuosa investigación, innovación y transformación social y urbana. Para esto hay que superar no solo la fragmentación, la a-sistematicidad y la discontinuidad de las políticas públicas de vivienda, hábitat y desarrollo urbano en el país, sino también la dispersión y la escasa acumulación de las múltiples investigaciones sociales sobre dichas políticas.

En este sentido, de manera contemporánea a la implementación del ProCreAr, se dieron en el país dos valiosas experiencias que, más allá de sus propias limitaciones (que no podemos abordar aquî), se orientaron a abordar distintas facetas de los problemas señalados en este artículo. Por un lado, producto de la articulación entre universidades públicas y organizaciones sociales y políticas -y después de más de cuatro años de intercambios en foros con multiplicidad de agentes e instituciones- en el año 2012 se aprobó en la provincia de Buenos Aires la Ley de Acceso Justo al Hábitat (Ley 14.449) la cual, además de reglamentar el derecho constitucional a tener un lugar adecuado para vivir en condiciones que favorezcan la integración social, fortaleció la capacidad estatal (provincial y municipal) para intervenir activamente en la remoción de los factores que históricamente han generado exclusión social y deterioro ambiental, generando mecanismos como: creación de un registro de demanda habitacional e instauración de un programa de lotes con servicios para producir suelo urbano; reconocimiento de la función social de la propiedad que permite movilizar parcelas inactivas y construcciones paralizadas; establecimiento de un sistema de compensación en suelo para el pago de la tasa por valorización de barrios cerrados, que busca incorporar suelo para nuevos barrios y viviendas, entre otros. Por otro lado, el "hábitat" fue uno de los temas identificados en el Núcleo Socio-Productivo sobre desarrollo social del Plan Nacional de Ciencia, Tecnología e Innovación "Argentina Innovadora 2020". Como resultado de las mesas de trabajo con expertos en el tema se lanzaron convocatorias específicas de investigaciones orientadas al mejoramiento de las condiciones y calidad de vida de la población a través del desarrollo de innovaciones en agua y energía para consumo y producción; viviendas de interés social adaptadas a las características territoriales y climáticas de cada región; y diseño, planificación y desarrollo de espacios rurales y urbanos.

El futuro de ambas iniciativas no parece promisorio: la implementación de la Ley de Acceso Justo al Hábitat ha encontrado la resistencia de los poderosos factores económicos y políticos que busca remover o, al menos, regular. Por otro lado las políticas públicas en ciencia y tecnología que impulsa el gobierno actual están caracterizadas por un proceso acelerado de desfinanciamiento, desestructuración y desmantelamiento. Pero ambas experiencias muestran los desafíos y las potencialidades que el hábitat -como realidad multidimensional en la que se intersectan factores económicos, sociales y ambientales- tiene para el desarrollo social y productivo del país y el lugar que la ciencia y la tecnología podrían ocupar en esos procesos. 
| Ciencia, Tecnología y Política | Año 2 | N² | Enero-Junio 2019 | ISSN 2618-3188 | www.revistas.unlp.edu.ar/CTyP |

\section{Bibliografía:}

AAVV (2015). Informe Bolsa de Comercio de Córdoba. Córdoba.

Bachiller, Santiago (Ed.) (2015). Tomas de tierras y dificultades de acceso al suelo urbano en la Patagonia central. Buenos Aires: Miño y Dávila.

Canestraro, María Laura (2016). "Sobre el derecho a la ciudad y el acceso al suelo urbano. Reflexiones a partir de intervenciones estatales recientes (Mar del Plata, 2012-2015)", en Estudios Socioterritoriales. Revista de Geografía, № 20, 57-74. Disponible en: http://www.scielo.org.ar/pdf/esso/v20/v20a05.pdf

Cosacov, Natalia y Segura, Ramiro (2017). "Pro.Cre.Ar. Bicentenario: azar, temporalidades, sentidos. La política pública desde sus beneficiarios", en Bordes. Revista de Política, Derecho y Sociedad. Vol. 6, 147-156. Disponible en: http://revistabordes.com.ar/la-politica-publica-desde-sus-beneficiarios/

Del Río, Juan Pablo (2017). "Crédito hipotecario, acceso al suelo y clase media en la implementación del Pro.Cre.Ar. en la ciudad de La Plata”, en María Cristina Cravino (Coord.). Detrás de los conflictos. Estudios sobre desigualdad urbana en la Región Metropolitana de Buenos Aires. Los Polvorines: Ediciones UNGS.

Di Virgilio, Mercedes y Rodríguez, Carla (2018). "Hábitat, vivienda y marginalidad residencial”, en Piovani, Juan Ignacio y Salvia, Agustín (Coord.) La Argentina en el siglo XXI. Cómo somos, vivimos y convivimos en una sociedad desigual. Buenos Aires: Siglo XXI.

Elinbaum, Pablo y Barenboim, Cintia (2017). “Efectos metropolitanos de una política de vivienda mixta. El caso del ProCreAr", en Cuadernos de Vivienda y Urbanismo, Vol. 11, № 21, 1-21. Disponible en: https:// revistas.javeriana.edu.co/index.php/cvyu/article/view/22093

Malizia, Matilde y Paolasso, Pablo (2009). "Countries y barrios privados en Yerba Buena, Gran San Miguel de Tucumán, Argentina: nuevas formas de expansión urbana”, en Estudios Demográficos y Urbanos, vol. 24, №3, 583-613. Disponible en: https://www.redalyc.org/pdf/312/31221533003.pdf

Segura, Ramiro (2017). "Desacoples entre desigualdades sociales, distribución del ingreso y patrones de urbanización en ciudades latinoamericanas. Reflexiones a partir de la Región Metropolitana de Buenos Aires (RMBA)", en Revista CS. No 21, 15-39. Disponible en: https://www.icesi.edu.co/revistas/index. php/revista_cs/article/view/2278 